\title{
The spectrum of myelodysplastic syndromes post-solid organ transplantation: A single institutional experience
}

\author{
M. Menes ${ }^{\text {a }}$, E. Vakiani ${ }^{\text {a }}$, C.E. Keller ${ }^{\text {a }}$, E.K. Ho ${ }^{\text {a }}$, A. Colovai ${ }^{\text {a }}$, G. Nichols ${ }^{\text {b }}$, D. Diuguid ${ }^{\text {b }}$, \\ J.G. Mears ${ }^{\text {b }, ~ V . V . ~ M u r t y ~}{ }^{\text {a }}$, B. Alobeid ${ }^{\mathrm{a}}$, G. Bhagat ${ }^{\mathrm{a}, *}$ \\ a Department of Pathology, College of Physicians and Surgeons, Columbia University, New York, NY 10032, USA \\ ${ }^{\mathrm{b}}$ Department of Medicine, Division of Hematology and Oncology, College of Physicians and Surgeons, Columbia University, New York, NY 10032, USA
}

Received 4 March 2006; received in revised form 21 April 2006; accepted 14 May 2006

Available online 19 June 2006

\begin{abstract}
An increased incidence of acute myeloid leukemia (AML) has recently been documented in patients post-solid organ transplantation but the incidence and types of myelodysplastic syndromes (MDS) occurring in this patient population are not known. We identified 5 patients (3M, 2F, age 48-64 years) who developed MDS ranging from 1.8 to 25 years (median 4.2 years) post-solid organ transplantation, only 2 patients had received azathioprine. The cumulative incidence of MDS in heart and lung transplant recipients at 15 years was $0.5 \%$ and $1.8 \%$, respectively, which is markedly higher compared to the general population. Low-risk types of MDS predominated, 3 of 5 patients are alive (median 3.9 years) since diagnosis. Deletions of chromosome 20q, which have not been previously reported in post-transplant MDS/AML, were identified in 3 cases. Our findings expand the morphologic and cytogenetic spectrum of MDS occurring post-solid organ transplantation and suggest that mechanisms beside azathioprine toxicity might be important in disease pathogenesis.
\end{abstract}

(C) 2006 Elsevier Ltd. All rights reserved.

Keywords: Myelodysplasia; Transplantation; Immunosuppression

\section{Introduction}

Myelodysplastic syndromes (MDS) are clonal hematopoietic stem cell disorders characterized by dysplastic maturation of one or more cell lineages leading to ineffective hematopoiesis, peripheral cytopenias and an increased risk of acute myeloid leukemia (AML) [1]. These disorders commonly occur in patients over the age of 60 [2]. The crude incidence of MDS is approximately 3.0/100,000 persons/year, which rises to $15-50 / 100,000$ persons/year for individuals over 70 years of age [2,3]. The etiology of MDS remains unclear but genetic insults, either inherited, e.g. Down syndrome and Fanconi anemia or acquired, the latter due to environmental exposure to toxins, radiation, or cytotoxic drugs, are thought to play important pathogenic roles $[4,5]$.

\footnotetext{
* Corresponding author. Tel.: +1 212342 1323; fax: +1 2123052301 .

E-mail address: gb96@columbia.edu (G. Bhagat).
}

Primary (de novo) and secondary forms of MDS are recognized, the latter commonly related to prior chemotherapy [6]. Chromosomal deletions, either complete or partial, involving chromosomes 5, 7, 20, 11 and 13 are the most commonly observed cytogenetic abnormalities in MDS [7] and a few of these have been linked to prior treatment with particular chemotherapeutic agents, e.g. chromosome 5 and 7 abnormalities following treatment with alkylating agents and balanced translocations of 11q23 (MLL) as a consequence of topoisomerase II inhibitor therapy $[6,8,9]$.

Acute leukemias and MDS occurring in recipients of solid organ transplants were either considered rare or thought to occur at rates similar to the general population [10-15]. However, recent studies have reported an increased risk of AML in patients who have undergone solid organ transplantation, which has largely been attributed to azathioprine toxicity $[10,11,16,17]$. The incidence and etiology of MDS post-solid organ transplantation are not well understood, although aza- 
thioprine induced DNA damage has also been implicated in the pathogenesis of these disorders [12,16,17]. Moreover, since chromosome 7 abnormalities are frequently observed in AML/MDS following treatment with azathioprine, mechanisms similar to alkylating therapy-associated MDS are thought to underlie MDS post-solid organ transplantation $[18,19]$.

We undertook this study to determine the incidence, morphologic spectrum, underlying cytogenetic abnormalities, and etiology of MDS post organ transplantation and assess the clinical outcomes of patients diagnosed with these disorders at our institute.

\section{Materials and methods}

\subsection{Case identification}

A retrospective search of our histopathology database was performed, over a 15-year period (1990-2004), to identify the number of bone marrow biopsy cases from patients post-solid organ transplantation. Results of clinical evaluation and pertinent laboratory tests, including peripheral blood counts, were correlated with morphologic findings of bone marrow biopsies to confirm the diagnosis of MDS. Biopsies from patients with a history of therapy for prior malignancies were excluded from analysis. Information regarding patient demographics, risk factors for MDS, underlying disease leading to transplantation, prior therapy and management, organ type transplanted, and peripheral blood counts (prior to transplantation and at the time of diagnosis of MDS), was obtained from our clinical laboratory database and the treating physicians. The study was performed in accordance with the guidelines of our institutional review board.

\subsection{Morphologic evaluation, immunohistochemical staining, and flow cytometry}

Hematoxylin-eosin (H\&E) stained bone marrow biopsies were used for morphologic review in conjunction with Wright-Giemsa and iron stained marrow aspirate smears and peripheral blood smears where available. All cases were classified according to the current WHO criteria [20]. Immunohistochemical (IHC) staining was performed on Bouins-fixed, paraffin-embedded bone marrow biopsy sections. Primary antibodies used included, CD34, CD117, CD61, myeloperoxidase (MPO), and glycophorin-A (DAKO, Carpinteria, CA), hMLH1 (BD Pharmingen, San Diego, CA), hMSH2 (Calbiochem, San Diego, CA), and hMSH6 (Invitrogen, Carlsbad, CA). After moist heat induced antigen retrieval, using citrate buffer ( $\mathrm{pH}$ 6.0) and low pH Target retrieval solution (DAKO) as applicable, the slides were stained on an autostainer (universal staining system, DAKO) using the Envision Plus system (DAKO) for detection and $\mathrm{DAB}$ as the chromogen. In situ hybridization for Epstein-
Barr virus early RNA (EBER; Ventana INFORM EBER, Tucson, AZ) was performed on all cases according to the supplied protocol. Three or four-color flow cytometric analysis (FACScan; Becton Dickinson, San Diego, CA, USA) was performed on the bone marrow aspirates or peripheral blood using the Cell Quest software (Becton Dickinson) according to standard procedures. T-, B-, NK-cell, and myeloid lineage specific antigens were analyzed using a comprehensive panel of monoclonal antibodies.

\subsection{Karyotype and fluorescent in situ hybridization (FISH) analysis}

Giemsa banding of metaphase preparations was performed using standard methods and the karyotypes were described according to ISCN 1995 [21]. FISH analysis was performed on fixed cells with the EGR1/D5S23 and D20S108 probes (VYSIS, Downers Grove, IL, USA) using standard protocols; 200-500 cells were analyzed and fluorescence signals were captured after counterstaining with DAPI using the Cytovision Imaging system attached to a Nikon Eclipse 600 microscope (Applied Imaging, Santa Clara, CA, USA).

\subsection{Statistical analysis}

The cumulative incidence of MDS for patients at risk was calculated using the Kaplan-Meier (K-M) method with the BMDP release 7 software (BMDP statistical software Inc., University of California Press, CA).

\section{Results}

\subsection{Prevalence and incidence of MDS post heart and lung transplantation}

A total of 1332 heart (age range 13 days-74 years) and 359 lung, including 31 combined heart and lung (age range 4 months-67 years) transplants were performed at our institute during the 15 year (1990-2004) study period. The period prevalence of MDS in heart and lung transplant recipients, combined, was 4/1691 (0.24\%) and the crude incidence of MDS was 10/100,000/year and 37/100,000/year post heart and lung transplantation, respectively. However, the cumulative incidence of MDS in heart and lung transplant recipients, determined by the $\mathrm{K}-\mathrm{M}$ method, was $0.5 \%$ and $1.8 \%$ at 15 years, respectively, which is higher compared to the crude incidence; 730 patients (501 post heart and 229 post lung transplantation) died and 115 patients (102 post heart and 13 post lung transplantation) were lost to follow-up at variable time points during the study period (censored data). Standardized incidence ratio and relative risk, as reported for AML post-transplantation [16,22], could not be calculated since there are no national or regional data regarding the incidence of MDS in the United States. The incidence of MDS post renal transplantation could not be determined due to lack 
Table 1

Clinico-pathologic characteristics of patients with MDS

\begin{tabular}{|c|c|c|c|c|c|c|c|c|}
\hline & $\begin{array}{l}\text { Age at Dx } \\
\text { (years)/ } \\
\text { gender }\end{array}$ & Organ Tx & $\begin{array}{l}\text { Underlying } \\
\text { disease }\end{array}$ & $\begin{array}{l}\text { Time from } \\
\text { Tx to MDS } \\
\text { (years) }\end{array}$ & $\begin{array}{l}\text { Immunosupressive } \\
\text { therapy }\end{array}$ & $\begin{array}{l}\text { WHO } \\
\text { classifi- } \\
\text { cation }\end{array}$ & $\begin{array}{l}\text { Outcome } \\
\text { (years) }\end{array}$ & Karyotype \\
\hline Patient 1 & $60 / \mathrm{M}$ & Heart & $\begin{array}{l}\text { Ischemic } \\
\text { cardiomyopathy }\end{array}$ & 4.2 & $\begin{array}{l}\text { Prednisone } \\
\text { mycophenolate } \\
\text { cyclosporine }\end{array}$ & \multicolumn{2}{|c|}{$\begin{array}{l}\text { MDS/MPD,A (3.9) } \\
\mathrm{U}\end{array}$} & $\begin{array}{l}\text { 46,XY,del(5)(q12q22[5]/46,XY, } \\
\text { idem,del(13)(q14)[3]/46,XY[4] }\end{array}$ \\
\hline Patient 2 & $48 / \mathrm{F}$ & Kidney $^{\mathrm{a}}$ & Scleroderma & $25^{\mathrm{a}}$ & $\begin{array}{l}\text { Cyclosporine } \\
\text { prednisone } \\
\text { azathioprine }\end{array}$ & RCMD & A (8.3) & $46, X X[8] / 46, X X, \operatorname{del}(20)(q 11)[13]$ \\
\hline Patient 3 & $53 / \mathrm{M}$ & Bilateral lung & UIP & 1.8 & $\begin{array}{l}\text { Cyclosporine } \\
\text { prednisone } \\
\text { azathioprine }\end{array}$ & RA & $\mathrm{A}(1.2)$ & $46, X Y, \operatorname{del}(20)(q 11)[2] / 46, X Y[19]$ \\
\hline Patient 4 & $62 / \mathrm{F}$ & Single lung & UIP & 3.2 & $\begin{array}{l}\text { Cyclosporine } \\
\text { mycophenolate } \\
\text { prednisone }\end{array}$ & RAEB-1 & $\mathrm{D}(0.5)$ & $\begin{array}{l}41-47, \mathrm{XX}, \mathrm{t}(4 ; 15)(\mathrm{q} 12 ; \mathrm{p} 11.2), \\
-5,-8,-11,-13,-15,-17,-19, \\
\operatorname{add}(19)(\mathrm{p} 13), \operatorname{del}(20)(\mathrm{q} 11.2),+\mathrm{r}(?), \\
+\operatorname{mar} 1-7[\mathrm{cp} 21] / 46, \mathrm{XX}[3]\end{array}$ \\
\hline Patient 5 & $64 / \mathrm{M}$ & Heart & $\begin{array}{l}\text { Ischemic } \\
\text { cardiomyopathy }\end{array}$ & 4.4 & $\begin{array}{l}\text { Cyclosporine } \\
\text { prednisone }\end{array}$ & RA & LTF & Not performed \\
\hline
\end{tabular}

Abbreviations: MDS, myelodysplastic syndrome; Dx, diagnosis; Tx, transplant; UIP, usual interstitial pneumonia; MPD, myeloproliferative disorder; U, unclassified; RA, refractory anemia; RAEB, refractory anemia with excess blasts; RCMD, refractory anemia with multilineage dysplasia; A, alive; D, dead; LTF, lost to follow-up.

a Patient underwent three successive kidney transplantations for membranous glomerulonephritis, year of first transplant 1972.

of follow-up care of many renal transplant patients at our institution.

\subsection{Clinico-pathologic characteristics}

Detailed clinical information, histologic findings, and results of cytogenetic analysis for each patient with MDS are described below. In brief, 3 males and 2 females (age range 48-64 years, mean 57.4 years, median 60 years) who had undergone solid organ transplantation (heart [ $n=2]$, lung $[n=2]$, and kidney $[n=1])$ fulfilled the clinico-pathologic criteria for MDS (Table 1). The marrow was hypercellular in 1, normocellular in 2, and hypocellular in 2 patients. Iron stores were either normal or increased and ringed sideroblasts were not identified. Loss of staining for DNA mismatch repair (MMR) proteins, hMLH1, hMSH2, and hMSH6 was not observed in any case, nuclear staining was observed in immature myeloid cells, monocytes, and rare megakaryocytes. ISH for EBER was negative in all cases. None of the patients had a history of prior malignancy or hematological disorder but one patient had long-standing autoimmune disease (scleroderma). All patients had a normal CBC post-transplantation and were on maintenance immunosuppressive regimens with different drug combinations, only 2 had received azathioprine (Table 1). Median time from transplantation to diagnosis of MDS was 4.2 years (range 1.8-25 years, mean 7.7 years). None of the patients received any therapy for MDS. Three of 5 patients are still alive with a median survival of 3.9 years post diagnosis (range 1.2-8.3 years, mean 4.5 years); including 1 who developed T-lymphoblastic lymphoma (T-LBL). One patient developed AML 4 months post diagnosis and died of infectious complications 2 months later, 1 patient was lost to follow-up immediately post diagnosis.

\subsection{Patient 1}

A 60-year-old man who underwent cardiac transplantation in 1997 for ischemic cardiomyopathy was noted to have an elevated WBC count $\left(24.7 \times 10^{9} / 1\right)$, normocytic normochromic anemia (Hgb 11), and thrombocytopenia $\left(94 \times 10^{9} / 1\right)$ on a routine examination in early 2002. A bone marrow biopsy and aspirate showed hypercellular marrow (90\%) with mildly left shifted myeloid hyperplasia (M:E-8:1), and megakaryocytic hyperplasia with dysplasia, consistent with an unclassifiable myelodysplastic/myeloproliferative (MDS/MPD-U) disorder. Karyotype analysis showed $\operatorname{del}(5)(\mathrm{q} 14 \mathrm{q} 22)$. FISH analysis using EGR1/D5S23 probes showed a normal signal pattern, confirming that the cytogenetic deletion did not encompass the EGR1 locus (5q31). His immunosuppressive regimen had consisted of prednisone, mycophenolate mofitil, and cyclosporine. The cumulative dose of cyclosporine received prior to diagnosis of MDS/MPD was $330.7 \mathrm{~g}$ (175 mg/day for 63 months, December 1997-February 2002). A few months post diagnosis he developed supraclavicular lymphadenopathy. An excisional biopsy revealed a precursor T-LBL that was CD4+ CD8+ ('double positive') and expressed CD56. PCR for TCR- $\gamma$ gene rearrangement showed a polyclonal product. Karyotype analysis demonstrated del(5)(q14q22) suggesting a lymphoblastic transformation of his underlying MDS/MPD. He received chemotherapy with cyclophosphamide, cytosine, cytarabine, methotrexate, and 6-mercaptopurine. Eight months later he developed splenomegaly and pancytopenia (WBC $\left.0.2 \times 10^{9} / 1\right)$. A repeat bone marrow biopsy and aspirate showed findings similar to those observed previously. Splenectomy, revealed an enlarged spleen (1500 g) and exten- 
sive extramedullary hematopoiesis with left shifted myeloid and monocytic cells in the red pulp and rare blasts $(<1 \%)$. Karyotype analysis revealed del(13)(q14) in addition, to del(5)(q14q22). His last CBC (January 2005) showed mild anemia (Hgb $11.5 \mathrm{~g} / \mathrm{dl})$, elevated WBC count $\left(102 \times 10^{9} / \mathrm{l}\right)$, normal platelet count $\left(172 \times 10^{9} / \mathrm{l}\right)$, and an absence of absolute monocytosis. He is currently alive, 3.9 years since diagnosis.

\subsection{Patient 2}

A 48-year-old woman with long-standing scleroderma underwent cadaveric renal transplantation in 1972 for renal failure due to membranous glomerulonephritis and was retransplanted twice, 4 and 15 years after her first transplant (the latter from a living related donor), for graft failure due to chronic rejection. She was found to be anemic (Hgb 8.9) with an elevated MCV (121 fl) on routine examination in 1997 but her WBC and platelet counts were within normal range. A bone marrow biopsy showed hypocellular marrow $(30 \%)$ with trilineage dysplasia and mild relative erythroid hyperplasia with megaloblastic features (M:E-1:2), consistent with refractory cytopenia with multilineage dysplasia (RCMD). Karyotype analysis showed del(20)(q11). Her immunosuppressive regimen had consisted of azathioprine $(50 \mathrm{mg} /$ day for 40 months, June 1971-June 1996 and $100 \mathrm{mg}$ for 13 months, July 1996-August 1997; cumulative dose prior to diagnosis of MDS - $480 \mathrm{~g}$ ) and different combinations of other drugs, including cyclosporine $(200 \mathrm{mg} /$ day for 314 months, June 1971-August 1997; cumulative dose $1884 \mathrm{~g}$ ) and prednisone. She has undergone excisional skin biopsies for multiple squamous cell and basal cell carcinomas but is currently alive 8.3 years since diagnosis of MDS. Her last CBC (October 2005) showed a mildly elevated WBC count $\left(14.9 \times 10^{9} / 1\right)$, normal platelet count, and a normal hemoglobin level $(14.8 \mathrm{~g} / \mathrm{dl})$ on maintenance erythropoietin therapy.

\subsection{Patient 3}

A 53-year-old man who had undergone bilateral lung transplantation in early 2002 for pulmonary failure due to usual interstitial pneumonia (UIP) was found to have pancytopenia (WBC $2.9 \times 10^{9} / \mathrm{l}, \mathrm{Hgb} 10.1 \mathrm{~g} / \mathrm{dl}$ and PLT $61 \times 10^{9} / \mathrm{l}$ ) and an elevated MCV (105.6fl) on routine follow-up exam in late 2003. His past medical history was significant for smoking (1 pack/day) since the age of 16 and he had worked for several years in the welding and sheet metal manufacturing industry. Bone marrow biopsy and aspirate in 2003 showed mildly hypocellular marrow (40\%) and moderate relative erythroid hyperplasia with megaloblastic change and dysplasia (M:E-1:3), consistent with refractory anemia (RA). Karyotype analysis showed del(20)(q11) and FISH with the D20S108 probe showed $7 \%$ of cells with chromosome 20q deletion. His maintenance immunosuppression had consisted of cyclosporine $(400 \mathrm{mg} /$ day for 22 months, January 2002-October 2003; cumulative dose prior to diagnosis of MDS-264 g), azathioprine $(100 \mathrm{mg} /$ day for 15 months, October 2000-December 2001; cumulative dose $-45 \mathrm{~g}$ ), and prednisone. He is currently alive 1.2 years since diagnosis. His last CBC (November, 2005) showed persistent anemia (Hgb $10.9 \mathrm{~g} / \mathrm{dl})$ and normal WBC and platelet counts.

\subsection{Patient 4}

A 62-year-old woman who had undergone a single lung transplant for UIP in 2001 presented with complaints of increasing fatigue and malaise in mid 2004. Hematologic work up showed pancytopenia (WBC $2.9 \times 10^{9} / 1, \mathrm{Hgb}$ $8.2 \mathrm{~g} / \mathrm{dl}$, and PLT $\left.42 \times 10^{9} / \mathrm{l}\right)$ and elevated MCV (112.4 fl). Bone marrow biopsy and aspirate showed normocellular marrow $(50 \%)$ with left shifted myeloid maturation (M:E-3:1), megaloblastic changes and dysplasia of the erythroid lineage, megakaryocytic dysplasia, and 6\% blasts, consistent with refractory anemia with excess blasts-type 1 (RAEB1). Blasts were also noted on the peripheral blood smear and had the following phenotype: CD34+, CD117+, CD13+, and MPO+. Cytogenetic analysis demonstrated a complex karyotype including del(20)(q11.2), -5 , and -13 (see Table 1). Her maintenance immunosuppression had consisted of cyclosporine (300 mg/day for 39 months, April 2001-May 2004; cumulative dose prior to diagnosis of MDS-351 g) mycophenolate mofitil, and prednisone. Increased blasts (22\%) were noted in the peripheral blood 4 months post diagnosis, consistent with AML. She died of infectious complications 2 months later.

\subsection{Patient 5}

A 64-year-old man who had undergone a heart transplant for ischemic cardiomyopathy in early 1990 presented with a paratracheal mass in 1994 that on biopsy showed a Bcell, polymorphic, post-transplant lymphoproliferative disorder (PTLD). Hematologic work-up demonstrated macrocytic anemia (Hgb 8.7 g/dl, MCV $102 \mathrm{fl}$ ) and his WBC and platelet counts were within normal range. A staging marrow biopsy showed normocellular marrow (50\%), mild absolute erythroid hyperplasia (M:E-1:2) with megaloblastic features and dysplasia, consistent with RA. There was no evidence of marrow involvement by lymphoma; cytogenetic analysis was not performed. His immunosuppressive regimen had consisted of cyclosporine ( $300 \mathrm{mg} /$ day for 53 months, January 1990-May 1994; cumulative dose prior to diagnosis of MDS $-477 \mathrm{~g}$ ) and prednisone. He was lost to follow-up shortly after diagnosis.

\section{Discussion}

Recipients of solid organ transplants are at an increased risk for developing diverse types of malignancies, espe- 
cially lymphomas, as a consequence of prolonged therapeutic immunosuppression [23]. Acute leukemias, including AML and acute lymphoblastic leukemia (ALL), have been reported to occur at variable time intervals post-solid organ transplantation $[10,11,15,16,22,25]$. These malignancies were considered sporadic events in the past, however, recent large single and multi-institutional studies have reported an increased incidence of AML post renal [16], liver [22], heart [11,16], and lung transplantation [16]. Moreover, the relative risk for developing AML has been shown to be higher post heart and lung transplantation compared to renal transplantation [16]. Dysplastic hematopoiesis, commonly observed following solid organ transplantation, is thought to have a multifactorial but non-neoplastic etiology [29]. Only a few reports and small case series have described MDS in recipients of solid organ allografts [10-12,14,16,26-28,30-32], mostly in recipients of renal transplants. However, data regarding the incidence and morphogenetic spectrum of MDS post-solid organ transplantation are limited.

Our study is the first to provide data regarding the cumulative incidence of MDS post heart and lung transplantation. The cumulative incidence of MDS at 15 years was $0.5 \%$ and $1.8 \%$ post heart and lung transplantation, respectively, which is 2.6-9.5 and 9.5-34.3-fold higher than the incidence of MDS reported for the general population [2,3]. The prevalence of MDS post heart and lung transplantation at our institution $(0.24 \%)$ is similar to that estimated from the data of Huebner et al. [11] for heart transplant recipients $(0.32 \%)$. The age at diagnosis of MDS of our patients is also in accord with published observations that report a younger age ( $<50$ years) for kidney transplant recipients compared to patients post heart and lung transplantation ( $>60$ years) [11,16,26-28]. A review of the literature, however, revealed a wide age range (28-72 years) of patients developing MDS post-solid organ transplantation [10-12,14,16,26-28,30-32], which is not dissimilar to that reported for individuals with primary MDS [1] or therapy-related MDS [33], including those with MDS following thiopurine therapy for nonneoplastic diseases [34].

A higher incidence of lower risk MDS (RA and RCMD) was seen in our series that was associated with a longer median survival (3.9 years) although, evolution to AML and T-LBL occurred in one patient each. The survival time of our patients is within the range reported for young adults who have a higher prevalence of RA [35] but the median age was similar to the population at risk for primary MDS [5]. Our findings are in contrast to the majority of previous studies, which described high risk types of MDS with frequent transformation to AML and a poor prognosis [11,12,16,28]. Since most of the published studies either predated the WHO classification or used the FAB classification, cases described as RAEB-T would now be considered AML [16,36]. Only a single case of refractory anemia with ringed sideroblasts was described in the report by Offman et al. [16]. Chronic myeloproliferative disorders, including CML, have been described post-solid organ transplantation [24], how- ever, a MDS/MPD “overlap" disorder, as observed in one of our patients, could not be identified in a search of the English literature.

MDS in the majority of our patients were associated with normocellular or hypocellular marrow. Occasional cases of hypocellular MDS have been reported post-solid organ transplantation $[16,26]$ but since most of the published reports did not quantify marrow cellularity, it is unclear if low cellularity is a unique feature of MDS in the post-transplant setting. Hypoplasia of one or more hematopoietic lineages is not uncommon in recipients of organ allografts. The underlying mechanisms are not well understood, however, immunosuppressive drug toxicity has been implicated in some cases [29,37,38]. Another interesting finding of our study, also observed by Clatch et al. [29] and Kim et al. [39], is the predominance of erythroid dyspoiesis, especially megaloblastic change in the absence of folate or Vitamin B12 deficiency. Azathioprine toxicity has been considered responsible for this phenomenon [39] since megaloblastoid erythropoiesis is also seen in patients with collagen-vascular disease treated with azathioprine [40-43]. Although azathioprine therapy might have contributed to erythroid macrocytosis in a few patients, we consider erythrocytic dysplasia to be a consequence of the neoplastic process. Three of 4 patients who had erythroid or erythroid and megakaryocytic dysplasia demonstrated del(20q), an abnormality that has not been associated with azathioprine therapy. It is of interest to note that a predominance of erythroid and megakaryocytic dysplasia has been described in MDS associated with del(20q), which has been postulated to be due to loss of genes located on chromosome $20 \mathrm{q}$ that might be critical for megakaryocytic and erythroid progenitor cell development or function [44].

The pathogenesis of post-transplant MDS is not well understood but azathioprine toxicity has been considered an important risk factor [16]. Chromosomal breaks and other cytogenetic abnormalities have been observed in marrow aspirates from patients treated with azathioprine [45] and spontaneous remission of RA associated with monosomy 7 was reported in a renal transplant patient upon discontinuation of azathioprine [27]. A whole host of cytogenetic abnormalities, mostly numerical, have been described in patients with MDS post-transplant, including del(1), -5, -7, $+8, \operatorname{del}(5 q), \operatorname{del}(6 q), \operatorname{del}(7 q), \operatorname{del}(9 q), \operatorname{del}(17 p),-17,-18$, $-19,-20$ and $-21[11,12,16,32]$. Many of these aberrations are similar to those observed in therapy-related MDS [46], which lead to deregulation of multiple distinct genetic pathways [47]. A search of the literature did not yield any reports of del(20q) in post-transplant MDS/AML. Chromosome 7 abnormalities, the most commonly reported cytogenetic aberrations in post-transplant MDS and alkylating therapy-related MDS, including cases associated with azathioprine therapy $[16,27,30,31,46,48]$, were not detected in any of our patients.

At the molecular level, defects in MMR, possibly due to epigenetic silencing of enzymes mediating this process, have been demonstrated in patients with post-transplant MDS [16] treated with azathioprine (but not other immunosuppressive 
drugs) [16]. MMR defects have also been observed in other forms of therapy-related MDS but not de novo MDS [49]. Individuals with thiopurine methyltransferase (TPMT) polymorphisms, leading to low levels of this enzyme, are thought to be at increased risk for developing MDS [50,51]. We performed staining for MMR proteins due to unavailability of genomic DNA. Absence of staining, considered an indirect marker for MMR deficient or microsatellite instability high (MSI+) neoplasms, was not observed in any case. Since staining for MMR proteins lacks sufficient sensitivity [52,53], our findings do not rule out the possibility of MMR deficiency in some of the cases.

Pre-transplant risk factors, cigarette smoking and longstanding autoimmune disease, could have contributed to the development of MDS in two of our patients. Autoimmune mechanisms have been proposed in the pathogenesis of at least a subset of patients with MDS [54,55] and autoimmune disorders, including SLE and Sjogrens syndrome, can be observed in approximately $10 \%$ of MDS patients [55]. An absence of known risk factors in other patients, however, suggests a role for immunosuppression in disease pathogenesis. An increased incidence of MDS has been reported in pediatric patients treated with cyclosporine for acquired aplastic anemia [56,57]. Decreased immune surveillance could potentially allow the survival of hematopoietic progenitors that incurred mutagenic insults either prior to or post organ transplantation.

In summary, we identified an increased incidence of MDS in individuals post heart and lung transplantation. The majority of our patients had low-risk types of MDS and, in contrast to previous reports, del(20q) was the most common cytogenetic abnormality observed. Since the clinical course of patients with MDS post organ transplantation can be relatively indolent and the dysplastic changes often subtle, cytogenetic analysis of bone marrow aspirates is critical in the diagnostic evaluation of unexplained cytopenias in these patients. The etiology of MDS post-solid organ transplantation appears multifactorial but immunosuppression likely plays an important role. Future large-scale genome analyses, similar to those employed in determining risk factors for therapy-related AML [58], might help elucidate important susceptibility factors for MDS/AML post-solid organ transplantation.

\section{References}

[1] Hofmann WK, Koeffler HP. Myelodysplastic syndrome. Annu Rev Med 2005;56:1-16

[2] Aul C, Gattermann N, Schneider W. Epidemiological and etiological aspects of myelodysplastic syndromes. Leuk Lymphoma 1995; 16:247-62.

[3] Aul C, Germing U, Gattermann N, Minning H. Increasing incidence of myelodysplastic syndromes: real or fictitious? Leuk Res 1998;22:93-100.

[4] Strom SS, Gu Y, Gruschkus SK, Pierce SA, Estey EH. Risk factors of myelodysplastic syndromes: a case-control study. Leukemia 2005;19:1912-8.
[5] Hofmann WK, Ottmann OG, Ganser A, Hoelzer D. Myelodysplastic syndromes: clinical features. Semin Hematol 1996;33:177-85.

[6] Pedersen-Bjergaard J, Philip P. Two different classes of therapyrelated and de novo acute myeloid leukemia? Cancer Genet Cytogenet 1991;55:119-24.

[7] Alvarez S, Cigudosa JC. Gains, losses and complex karyotypes in myeloid disorders: a light at the end of the tunnel. Hematol Oncol 2005;23:18-25.

[8] Leone G, Mele L, Pulsoni A, Equitani F, Pagano L. The incidence of secondary leukemias. Haematologica 1999;84:937-45.

[9] Pedersen-Bjergaard J, Andersen MK, Christiansen DH, Nerlov C. Genetic pathways in therapy-related myelodysplasia and acute myeloid leukemia. Blood 2002;99:1909-12.

[10] Thalhammer-Scherrer R, Wieselthaler G, Knoebl P, Schwarzinger I, Simonitsch I, Mitterbauer G, et al. Post-transplant acute myeloid leukemia (PT-AML). Leukemia 1999;13:321-6.

[11] Huebner G, Karthaus M, Pethig K, Freund M, Ganser A. Myelodysplastic syndrome and acute myelogenous leukemia secondary to heart transplantation. Transplantation 2000;70:688-90.

[12] Kobbe G, Germing U, Aivado M, Zohren F, Schubert D, Strupp C, et al. Treatment of secondary myelodysplastic syndrome after heart transplantation with chemotherapy and nonmyeloablative stem-cell transplantation. Transplantation 2002;74:1198-200.

[13] Penn I. Solid tumors in cardiac allograft recipients. Ann Thorac Surg 1995;60:1559-60.

[14] Forster E, Birnbacher R, Mann G, Balzar E, Radaszkiewicz T, Urbanek R. Myelodysplastic syndrome with signs of auto-immune disease in a patient with renal allograft. Eur J Pediatr 1998;157:351.

[15] Arican A, Ozbek N, Baltaci V, Haberal M. Philadelphia chromosome (+) T-cell acute lymphoblastic leukemia after renal transplantation. Transplant Proc 1999;31:3242-3.

[16] Offman J, Opelz G, Doehler B, Cummins D, Halil O, Banner NR, et al. Defective DNA mismatch repair in acute myeloid leukemia/myelodysplastic syndrome after organ transplantation. Blood 2004;104:822-8.

[17] Subar M, Gucalp R, Benstein J, Williams G, Wiernik PH. Acute leukaemia following renal transplantation. Med Oncol 1996;13: 9-13.

[18] Knipp S, Hildebrandt B, Richter J, Haas R, Germing U, Gattermann N. Secondary myelodysplastic syndromes following treatment with azathioprine are associated with aberrations of chromosome 7. Haematologica 2005;90:691-3.

[19] Kwong YL, Au WY, Liang RH. Acute myeloid leukemia after azathioprine treatment for autoimmune diseases: association with $-7 / 7 \mathrm{q}$. Cancer Genet Cytogenet 1998;104:94-7.

[20] Jaffe E, Harris N, Stein H, Vardiman J, editors. Pathology and genetics: tumours of Haematopoietic and lymphoid tissues. Lyon: IARC Press; 2001.

[21] Mitelman. An international system for human cytogenetic nomenclature. In: Mitelman, editor. International standing committee on human cytogenetic nomenclature. Basel, Switzerland; 1995.

[22] Camos M, Esteve J, Rimola A, Grande L, Rozman M, Colomer D, et al. Increased incidence of acute myeloid leukemia after liver transplantation? Description of three new cases and review of the literature. Transplantation 2004;77:311-3.

[23] Trofe J, Beebe TM, Buell JF, Hanaway MJ, First MR, Alloway RR, et al. Posttransplant malignancy. Prog Trans 2004;14:193-200.

[24] Pelloso LA, Campos MG, Nascimento M, Silva MR, Pestana JO, Chauffaille Mde L. Chronic myeloid leukemia following kidney transplantation. Leuk Res 2005;29:353-5.

[25] Levendoglu-Tugal O, Weiss R, Ozkaynak MF, Sandoval C, Lentzner B, Jayabose S. T-cell acute lymphoblastic leukemia after renal transplantation in childhood. J Pediatr Hematol Oncol 1998;20:54851.

[26] Ihle BU, Constable J, Gordon S, Mahony JF. Myelodysplasia in cadaver renal allografts: a report of four cases. Am J Kidney Dis 1985;5:2517. 
[27] Renneboog B, Hansen V, Heimann P, De Mulder A, Jannsen F, Ferster A. Spontaneous remission in a patient with therapy-related myelodysplastic syndrome (t-MDS) with monosomy 7. Br J Haematol 1996;92:696-8.

[28] Okamoto T, Okada M, Itoh T, Mori A, Saheki K, Takatsuka H, et al. Myelodysplastic syndrome with B cell clonality in a patient five years after renal transplantation. Int J Hematol 1998;68:61-5.

[29] Clatch RJ, Krigman HR, Peters MG, Zutter MM. Dysplastic haemopoiesis following orthotopic liver transplantation: comparison with similar changes in HIV infection and primary myelodysplasia. $\mathrm{Br}$ J Haematol 1994;88:685-92.

[30] Depil S, Lepelley P, Soenen V, Preudhomme C, Lai JL, Broly $\mathrm{F}$, et al. A case of refractory anemia with $17 \mathrm{p}-$ syndrome following azathioprine treatment for heart transplantation. Leukemia 2004; 18:878.

[31] Wurthner J, Rump LC, Grotz W, Engelhardt R, Lubbert M. Management of acute myeloid leukaemia following myelodysplastic syndrome in a kidney graft recipient. Nephrol Dial Transplant 1999;14:501-6.

[32] Zhang GS, Dai CW, Peng HL, Xu YX, Pei MF. Myelodysplastic syndrome with transformation to acute monocytic leukemia with FLT(3)ITD mutation following orthotopic liver transplantation. Leuk Res 2006.

[33] Larson RA, Le Beau MM. Therapy-related myeloid leukaemia: a model for leukemogenesis in humans. Chem Biol Interact 2005;153-154:187-95.

[34] Arnold JA, Ranson SA, Abdalla SH. Azathioprine-associated acute myeloid leukaemia with trilineage dysplasia and complex karyotype: a case report and review of the literature. Clin Lab Haematol 1999;21:289-92.

[35] Breccia M, Mengarelli A, Mancini M, Biondo F, Gentilini F, Latagliata $\mathrm{R}$, et al. Myelodysplastic syndromes in patients under 50 years old: a single institution experience. Leuk Res 2005;29:749-54.

[36] Harris NL, Jaffe ES, Diebold J, Flandrin G, Muller-Hermelink HK, Vardiman J, et al. The World Health Organization classification of neoplasms of the hematopoietic and lymphoid tissues. Report of the Clinical Advisory Committee meeting; Airlie House, Virginia. November 1997. Hematol J 2000;1:53-66.

[37] Al-Uzri A, Yorgin PD, Kling PJ. Anemia in children after transplantation: etiology and the effect of immunosuppressive therapy on erythropoiesis. Pediatr Transplant 2003;7:253-64

[38] Escousse A, Mousson C, Santona L, Zanetta G, Mounier J, Tanter Y, et al. Azathioprine-induced pancytopenia in homozygous thiopurine methyltransferase-deficient renal transplant recipients: a family study. Transplant Proc 1995;27:1739-42.

[39] Kim CJ, Park KI, Inoue H, Yoshida T, Yoshiki T, Tomoyoshi T, et al. Azathioprine-induced megaloblastic anemia with pancytopenia 22 years after living-related renal transplantation. Int J Urol 1998;5:100-2.

[40] Urowitz MB, Smythe HA, Able T, Norman CS, Travis C. Longterm effects of azathioprine in rheumatoid arthritis. Ann Rheum Dis 1982;41(Suppl. 1):18-22.

[41] McGrath BP, Ibels LS, Raik E, Hargrave MJ. Erythroid toxicity of azathioprin. Macrocytosis and selective marrow hypoplasis. Q J Med 1975;44:57-63.

[42] Christoph R, Pirnay D, Hartl W. Megaloblastic anemia following treatment of rheumatoid arthritis with azathioprine. Med Welt 1971;46:1824-7.
[43] Lennard L, Murphy MF, Maddocks JL. Severe megaloblastic anaemia associated with abnormal azathioprine metabolism. Br J Clin Pharmacol 1984;17:171-2.

[44] Kurtin PJ, Dewald GW, Shields DJ, Hanson CA. Hematologic disorders associated with deletions of chromosome 20q: a clinicopathologic study of 107 patients. Am J Clin Pathol 1996;106:680-8.

[45] Jensen MK. Effect of azathioprine on the chromosome complement of human bone marrow cells. Int J Cancer 1970;5:147-51.

[46] Smith SM, Le Beau MM, Huo D, Karrison T, Sobecks RM, Anastasi J, et al. Clinical-cytogenetic associations in 306 patients with therapy-related myelodysplasia and myeloid leukemia: the University of Chicago series. Blood 2003;102:43-52.

[47] Pedersen-Bjergaard J, Pedersen M, Roulston D, Philip P. Different genetic pathways in leukemogenesis for patients presenting with therapy-related myelodysplasia and therapy-related acute myeloid leukemia. Blood 1995;86:3542-52.

[48] Rubin CM, Arthur DC, Woods WG, Lange BJ, Nowell PC, Rowley JD, et al. Therapy-related myelodysplastic syndrome and acute myeloid leukemia in children: correlation between chromosomal abnormalities and prior therapy. Blood 1991;78:2982-8

[49] Karran P, Offman J, Bignami M. Human mismatch repair, drug-induced DNA damage, and secondary cancer. Biochimie 2003;85:1149-60.

[50] Coulthard S, Hogarth L. The thiopurines: an update. Invest New Drugs 2005.

[51] Bo J, Schroder H, Kristinsson J, Madsen B, Szumlanski C, Weinshilboum R, et al. Possible carcinogenic effect of 6-mercaptopurine on bone marrow stem cells: relation to thiopurine metabolism. Cancer 1999;86:1080-6.

[52] Ruszkiewicz A, Bennett G, Moore J, Manavis J, Rudzki B, Shen L, et al. Correlation of mismatch repair genes immunohistochemistry and microsatellite instability status in HNPCC-associated tumours. Pathology 2002;34:541-7.

[53] Engel C, Forberg J, Holinski-Feder E, Pagenstecher C, Plaschke J, Kloor M, et al. Novel strategy for optimal sequential application of clinical criteria, immunohistochemistry and microsatellite analysis in the diagnosis of hereditary nonpolyposis colorectal cancer. Int J Cancer 2006;118:115-22.

[54] Sloand EM, Mainwaring L, Fuhrer M, Ramkissoon S, Risitano AM, Keyvanafar K, et al. Preferential suppression of trisomy 8 compared with normal hematopoietic cell growth by autologous lymphocytes in patients with trisomy 8 myelodysplastic syndrome. Blood 2005; 106:841-51.

[55] Voulgarelis M, Giannouli S, Ritis K, Tzioufas AG. Myelodysplasiaassociated autoimmunity: clinical and pathophysiologic concepts. Eur J Clin Invest 2004;34:690-700.

[56] Kojima S, Ohara A, Tsuchida M, Kudoh T, Hanada R, Okimoto Y, et al. Risk factors for evolution of acquired aplastic anemia into myelodysplastic syndrome and acute myeloid leukemia after immunosuppressive therapy in children. Blood 2002;100:786-90.

[57] Ohara A, Kojima S, Hamajima N, Tsuchida M, Imashuku S, Ohta S, et al. Myelodysplastic syndrome and acute myelogenous leukemia as a late clonal complication in children with acquired aplastic anemia. Blood 1997;90:1009-13.

[58] Bogni A, Cheng C, Liu W, Yang W, Pfeffer J, Mukatira S, et al. Genomewide approach to identify risk factors for therapy-related myeloid leukemia. Leukemia 2006;20:239-46. 